\title{
The utilization demineralized rice husk waste for biofuel source via pyrolysis: thermogravimetric analysis and kinetic study
}

\author{
Hesti Wijayanti ${ }^{1, *}$, Iryanti Fatyasari $\mathrm{Nata}^{1}$, and Rinny Jelita ${ }^{1}$ \\ ${ }^{1}$ Chemical Engineering Department, Lambung Mangkurat University, Indonesia
}

\begin{abstract}
Rice husk is considered as agricultural waste that causes environmental problem during its handling. In this study, rice husk was treated with acid (citric acid and nitric acid) solutions prior used as raw material for producing biofuel and chemicals via pyrolysis. The pyrolysis behaviors of rice husk treated with water and acid solutions have been investigated through thermogravimetric analysis from room temperature to $600^{\circ} \mathrm{C}$ at the heating rate of $10^{\circ} \mathrm{C} / \mathrm{min}$ under $50 \mathrm{ml} / \mathrm{min}$ nitrogen flow. Demineralization treatment using strong acid (nitric acid) solution showed more impacts to the rice husk in thermogravimetric analysis, i.e. lower ash content, less minerals content and thermal stability increased. One step model kinetic resulted the lowest activation energy $(12.8709 \mathrm{~kJ} / \mathrm{mol})$ occured at the $5 \%$ nitric acid solution treatment. Excellent agreement between the experimental data and model predictions was found with $8.63 \%$ of the relative error. In other words, demineralization using $5 \%$ nitric acid solution would improve rice husk performance during its pyrolysis reaction for producing biofuel.
\end{abstract}

Keywords: demineralization, kinetic, rice husk, thermogravimetric analysis

\section{Introduction}

As the country who depends on rice as the staple food, Indonesia has maintained the high production of rice. In 2015, the rice production in Indonesia was 75.36 million tons. It was increased about $6.37 \%$ compared to that in 2014 [1]. The huge amount of rice production is followed by the significant amount of rice husk and rice straw as the production waste. Prasara and Grant [2] estimated by-product of rice production in the form of rice husk accounts for $23 \%$ of the total paddy weight. In general, it is handled through composting and incineration. However, composting only contains small concentration of nitrogen while solid particulates and smoke those pollute the environment would be resulted from incineration [3].

Pyrolysis is one of the methods to utilize biomass producing fuel or chemicals through thermal decomposition at high temperature at no oxygen condition. The essential factors should be considered for design the pyrolysis unit effectively: biomass type, operating

\footnotetext{
* Corresponding author: hesti.wijayanti@ulm.ac.id
} 
conditions and reactor configuration[4]. Moreover, the content and composition of the minerals in the raw biomass also influence the pyrolysis result[5].

Different approaches have been used in biomass pretreatment prior to pyrolysis [6-11]. Luque et al. [12] reported the ash content of corn cobs was significantly decreased about $82-90 \%$ via demineralization with acetic or nitric acid solutions. Research by Park [10] found that the strong acid treatment of biomass caused mass losses, nitric acid $\left(\mathrm{HNO}_{3}\right)$ and hydrochloric acid $(\mathrm{HCl})$ washing caused $17 \%$ and $15 \%$ mass losses respectively. Work by Vamvuka et al. [13] observed that carbonates, sulphates and alkali chloride minerals were dissolved due to the $\mathrm{HCl}$ washing, however they only partially removed when a weaker acid (e.g. acetic acid) was used. Tan and Wang [7] have shown that the metal content of biomass was decreased after $\mathrm{HCl}$ washing, resulting an increase rate of volatiles released during pyrolysis.

The pyrolysis kinetic information is important for predicting the pyrolysis behavior of biomass materials as well as designing the suitable reactor [14]. The previous studies achieved remarkable results in understanding demineralization treatment of biomass prior to pyrolysis. However, the effect of water and acid washing to pyrolysis behavior and kinetic of rice husk has not been fully investigated.

This study investigated pyrolysis characteristics of treated and untreated rice husk with thermogravimetry analysis. Furthermore, their kinetic properties were determined to give better understanding about the rice husk pyrolysis. This result would be useful in pyrolysis reactor design for producing biofuel from the rice husk waste.

\section{Methodology}

\subsection{Demineralization treatment}

Rice husk that collected from Gambut village, Banjar district, South Kalimantan was powdered and sieved to the particle size of $0.25-1 \mathrm{~mm}$. The rice husk powder was dried in oven at $80^{\circ} \mathrm{C}$ for $3 \mathrm{~h}$. During demineralization treatment, $20 \mathrm{~g}$ of rice husk powder and 200 $\mathrm{ml}$ of distilled water (or 1, 5, $10 \mathrm{wt} \%$ of citric acid and nitric acid for acid washing) were mixed in a beaker then stirred at $300 \mathrm{rpm}$ for $2 \mathrm{~h}$. Afterwards the solution was vacuum filtered. The samples using acid solutions were rinsed with distilled water until $\mathrm{pH}$ neutral. The samples were dried in an oven at $80^{\circ} \mathrm{C}$ for $22 \mathrm{~h}$ and then stored in a sealed desiccator until further analysis. ASTM E1755 and ASTM D3175 were used to determine the proximate analysis (the fixed carbon was calculated by difference) of the samples. The contents of minerals in the samples were determined by X-Ray Fluorescence PANalytical / Minipal 4. Thermogravimetric analysis (TGA) and Differential Thermogravimetry Analysis (DTG) were performed using thermogravimetry analyzer Linseis STA PT 1600 with approximately $15 \mathrm{mg}$ of sample that was heated under $50 \mathrm{ml} / \mathrm{min}$ of nitrogen at a rate of $10^{\circ} \mathrm{C} / \mathrm{min}$ up to $600^{\circ} \mathrm{C}$.

\subsection{The kinetics of pyrolysis model}

The kinetic study of the rice husk pyrolysis was investigated using TGA data. The decomposition rate of a solid is generally given an equation in the form [15]:

$$
\frac{d \alpha}{d t}=k(T) f(\alpha)
$$

$\alpha$ is the mass conversion ratio and given as $\alpha=(m \mathrm{o}-m \mathrm{t}) /(m \mathrm{o}-m \mathrm{f})$, where $m \mathrm{o}, m \mathrm{t}$ and $m \mathrm{f}$ expressing the original, current (at time t) and final sample weight, respectively. $t$ is the 
time, $\mathrm{f}(\alpha)$ is the reaction model and $\mathrm{k}(T)$ is the rate constant which varies with the temperature according to Arrhenius' law:

$$
k(T)=A \exp \left(-\frac{E}{R T}\right)
$$

where $\mathrm{A}$ is the pre-exponential factor, $\mathrm{E}$ is the activation energy, $\mathrm{R}$ is the universal gas constant, $\mathrm{T}$ is the absolute temperature.

By combining the Eqs (1) and (2), the reaction rate can be written in the form:

$$
\frac{d \alpha}{d t}=A \exp \left(-\frac{E}{R T}\right) f(\alpha)
$$

It is assumed that conversion of material in biomass into products in a one-step process. The method for the kinetic analysis of the thermogravimetric curves is based on the following kinetic equation [16-23]:

$$
\frac{d \alpha}{d t}=A \exp \left(-\frac{E}{R T}\right)(1-\alpha)^{n}
$$

where $\mathrm{n}$ is the reaction order.

The first-order reaction is appropriate to describe the experimental data obtained by TGA [24]:

$$
\frac{d \alpha}{d t}=A \exp \left(-\frac{E}{R T}\right)(1-\alpha)
$$

For a constant heating rate $\beta$ during pyrolysis, $\beta=\mathrm{d} T / \mathrm{d} t$, Eqn (5) can be transformed into:

$$
\frac{d \alpha}{1-\alpha}=\frac{A}{\beta} \exp \left(-\frac{E}{R T}\right) d T
$$

Integration and linierization Eqn (6) yields:

$$
\ln \left[\frac{-\ln (1-\alpha)}{T^{2}}\right]=\ln \left(\frac{A R}{\beta E}\right)-\frac{E}{R T}
$$

A plot of $\ln \left[-\ln (1-\alpha) / T^{2}\right]$ vs $1 / T$ will yield the values of $A$ and $E$ from the intercept and the slope.

To justify the fit of the model, the mass of sample at $t$ (from the experiment) was compared to the one from the calculation. The calculated mass of sample at $t$ is yielded by integration Eqn (5):

$$
\ln \frac{1}{1-\alpha}=A \exp \left(-\frac{E}{R T}\right) t
$$

Substitution $\alpha=(m \mathrm{o}-m \mathrm{t}) /(m \mathrm{o}-m \mathrm{f})$, Eqn (8) becomes:

$$
m_{t}=m_{0}-\left(m_{0}-m_{f}\right)\left(1-\frac{1}{e^{A \exp \left(-\frac{E}{R T}\right) t}}\right)
$$

Average relative error in Eqn (10) is used to validate the fit of the model

$$
\text { Error }=\sum\left|\frac{m t_{\text {experiment }}-m t_{\text {calculation }}}{m t_{\text {experiment }}}\right| x 100 \%
$$




\section{Result and Discussion}

\subsection{The influence of demineralization treatment to the rice husk characteristics}

Table 1 summarizes the impact of the treatments on the rice husk properties resulted from proximate analysis. From Table 1, it can be concluded that the demineralization treatment significantly decreased the volatile matter and the ash content while fixed carbon was increase. However, the treatment with water slightly increased the ash content, possibly due to the high lignin composition combined with high potassium in rice husk that hardly removed [25]. The demineralization treatment with stronger acid solution (nitric acid), instead of citric acid resulted materials with lower ash content.

Table 1. The Proximate Analysis of Treated and Untreated Rice Husk

\begin{tabular}{|c|c|c|c|}
\hline Rice husk & Volatil matter & Fixed carbon & Ash \\
\hline Untreated & 76.36 & 8.29 & 15.35 \\
\hline Distilled water & 76 & 8.39 & 15.60 \\
\hline Citric acid, 1\% & 70.64 & 14.16 & 15.19 \\
\hline Citric acid, 5\% & 72.41 & 12.39 & 15.19 \\
\hline Nitric acid, 1\% & 72.98 & 11.72 & 15.30 \\
\hline Nitric acid, 5\% & 72.77 & 12.27 & 14.96 \\
\hline Nitric acid, 10\% & 68.97 & 15.85 & 15.18 \\
\hline
\end{tabular}

Treated and untreated rice husk were analyzed for the mineral contents that are presented in Table 2. From Table 2 one can concluded that potassium $(\mathrm{K})$, calsium $(\mathrm{Ca})$, manganese $(\mathrm{Mn})$ reduced significantly upon the treatment, especially $\mathrm{K}$, those totally removed due to acid treatment. $\mathrm{Mn}$ and $\mathrm{Ca}$ indicate they were dissolved much easier in acids than in water. Fe did not influence by water treatment, however it was slighly decreased after acid treatments. Meanwhile, $\mathrm{Cu}$ was not affected by both treatments, water and acid solutions.

Table 2. The Mineral Content of Treated and Untreated Rice Husk

\begin{tabular}{|c|c|c|c|c|c|}
\hline Rice husk & K & $\mathbf{C a}$ & $\mathbf{M n}$ & $\mathbf{F e}$ & $\mathbf{C u}$ \\
\hline Untreated & 9.38 & 5.05 & 1.4 & 1 & 0.4 \\
\hline Distilled water & 0.91 & 3.99 & 0.82 & 1 & 0.35 \\
\hline Citric acid, 1\% & n.d. $^{*}$ & 2.80 & 0.37 & 0.69 & 0.4 \\
\hline Citric acid, 5\% & n.d. $^{*}$ & 2.60 & 0.32 & 0.67 & 0.38 \\
\hline Nitric acid, 1\% & n.d. $^{*}$ & 2.3 & 0.2 & 0.7 & 0.39 \\
\hline Nitric acid, 5\% & n.d. $^{*}$ & 2.2 & 0.2 & 0.69 & 0.4 \\
\hline Nitric acid, 10\% & n.d. $^{*}$ & 2.2 & n.d. $^{*}$ & 0.68 & 0.39 \\
*n.d., not detected & & &
\end{tabular}




\subsection{Thermogravimetry Analysis}

The TGA curves of rice husk with and without demineralization treatment are plotted in Figure 1. It can be seen that from room temperature to approximately $200^{\circ} \mathrm{C}$ there was slight mass loss due to the moisture removal and degradation of the light organic compounds. The main thermal decomposition of rice husk took place from approximately 210 to $370^{\circ} \mathrm{C}$ which result in mass loss for about $56 \%$. Figure 1 also shows that rice husk pyrolysis occurred in single step decomposition, thus no more decomposition at higher temperature. Beyond $370^{\circ} \mathrm{C}$ there was carbonization step. At this step, the slowly mass loss decreases took place to the final temperature $\left(600^{\circ} \mathrm{C}\right)[15]$.

As presented in Table 3, the different demineralization treatment resulted in the different thermal degradation behavior. It shows that water and acid treatments could increase the initial decomposition temperature (Ti) and the temperature of maximum loss rate (Tmax). This implies the thermal stability of treated rice husk enhanced [15]. However, there is the change in solid residue left at $600^{\circ} \mathrm{C}$, which is linear to the strength of acids and also their concentrations, those made $10 \%$ of nitric acid gave the lowest $(21.66 \%)$.

Table 3. Thermal Degradation Characteristic of Treated and Untreated Rice Husk

\begin{tabular}{|c|c|c|c|c|}
\hline Samples & $\mathbf{T i}\left({ }^{\mathbf{0}} \mathbf{C}\right)$ & $\mathbf{T m a x}\left({ }^{\mathbf{0}} \mathbf{C}\right)$ & $\mathbf{T f}\left({ }^{\mathbf{0}} \mathbf{C}\right)$ & $\mathbf{M r}(\mathbf{w t .} \%)$ \\
\hline Untreated RH & 210 & 350 & 430 & 32.3384 \\
\hline Distilled water & 220 & 370 & 460 & 32.3039 \\
\hline Citric acid, 1\% & 220 & 360 & 460 & 29.3659 \\
\hline Citric acid, 5\% & 220 & 370 & 460 & 31.9823 \\
\hline Nitric acid, 1\% & 230 & 350 & 470 & 28.4848 \\
\hline Nitric acid, 5\% & 220 & 360 & 430 & 26.9145 \\
\hline Nitric acid, 10\% & 220 & 360 & 430 & 21.6555 \\
\hline
\end{tabular}

$\mathrm{Ti}$, the initial decomposition temperature.

Tmax, the temperature of maximum loss rate.

$\mathrm{Tf}$, the final decomposition temperature.

DTGmax, the mass loss rate of corresponding Tmax.

$\mathrm{Mr}$, the final residue mass.

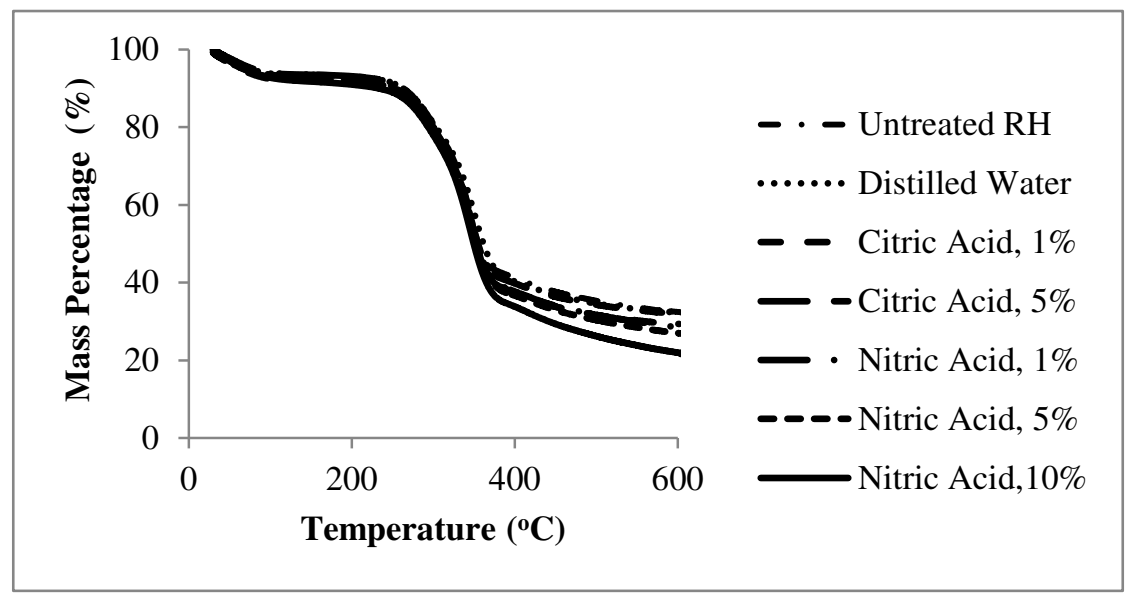

Fig 1. TGA curves of treated and untreated rice husk 


\subsection{Kinetic Analysis}

Kinetic calculations were carried out based on the assumptions and steps as explained in the Methodology section. The results of calculations are summarized in Table 4.

Tabel 4. Kinetic Properties of Treated and Untreated Rice Husk

\begin{tabular}{|c|c|c|c|c|}
\hline Rice Husk & Temperature $\left.^{\mathbf{0}} \mathbf{C}\right)$ & $\mathbf{E}(\mathbf{k J} / \mathbf{m o l})$ & $\mathbf{A ~ ( \mathbf { s } ^ { - \mathbf { 1 } } )}$ & Error (\%) \\
\hline Untreated RH & $30.9-604.4$ & 13.7655 & 0.0102 & 6.3642 \\
\hline Distilled water & $32.1-601.8$ & 13.3074 & 0.0089 & 7.9061 \\
\hline Citric acid, 1\% & $29.8-601.5$ & 13.1611 & 0.0091 & 8.1405 \\
\hline Citric acid, 5\% & $29.8-603$ & 15.6095 & 0.0162 & 7.1405 \\
\hline Nitric acid, 1\% & $30-603.4$ & 15.6794 & 0.0155 & 7.4005 \\
\hline Nitric acid, 5\% & $34.9-603.4$ & 12.8709 & 0.0076 & 8.6249 \\
\hline Nitric acid, 10\% & $31.6-603.7$ & 13.8569 & 0.0095 & 7.5008 \\
\hline
\end{tabular}

Table 4 presents that treatment using 5\% nitric acid solution resulted in the lowest activation energy. The low activation energy implies the energy needed for decomposition reaction also low, thus the reaction occured faster. Acid solution treatment effectively removed the minerals from the rice husk as observed by Tan [7]. Furthermore, nitric acid solution exhibited higher mineral removal than citric acid especially at the higher concentration (see Table 2). This strength of acid and its concentration also increased the quantity of ash that was removed [26]. The reduction of ash and minerals content in the rice husk possibly makes the bonds broken easily, thus energy needed for decomposition decreased. Because thermogravimetry apparatus is a model of pyrolysis reactor, by using this kinetic study it can be concluded that treatment using 5\% nitric acid solution could reduce consumed energy during pyrolysis reaction, as the main reaction in pyrolysis is decomposition reaction. However, rice husk that was treated using 10\% nitric acid solution produced higher activation energy, this means consumed energy during decomposition reaction also higher. The possible explanation is due to the acid concentration was too high that causes it became inhibitor during decomposition reaction. As reported by Reza et al (27), most of the structural ash in biomass is placed in the cross-linked structure of lignin, which is more reactive in slightly basic solutions. Compared to $10 \%$ nitric acid solution, $5 \%$ nitric acid solution is more basic. So, ash was easier to remove in $5 \%$ nitric acid solution than that of $10 \%$. As the result, rice husk treated using 5\% nitric acid solution needed lower energy to decompose.

\section{Conclusion}

The thermogravimetric analysis and kinetic study were conducted to the rice husk that treated with water and acid solutions (nitric acid and citric acid). The results revealed that ash content and minerals were decreased upon the treatment, especially the treatment with strong acid solution (nitric acid at high concentration). This treatment also increased the thermal stability of the treated rice husk. From the kinetic study, 5\% nitric acid solution showed the lowest activation energy, so that energy needed to decompose it also low. In other words, the 5\% nitric acid solution treatment could reduce the consumed energy during rice husk pyrolysis for biofuel production. However, at the highest concentration of nitric acid solution (10\%), the activation energy was higher than that of untreated rice husk. This 
possibly because the acid concentration was too high that makes it became inhibitor during decomposition reaction.

\section{References}

1. Biro Pusat Statistik, https://www.bps.go.id/brs/view/id/1271 accessed on January 30, 2017 (2016)

2. J. Prasara, T. Grant, Environmental impacts of alternative uses of rice husks for Thailand, Proceeding The 6th International Conference on LCA in the Agri-Food Sector, Zurich, November 12-1, 2008

3. Z. Ji-lu, J. Anal. Appl. Pyrol., 80, 30-35 (2017)

4. A.V. Bridgwater, Biomass and Bioenergy, 38, 68-94 (2012)

5. L. Quanrum, H. Haoquan, Z. Qiang, Z. Shengwei, C. Gouohua, Fuel, 8, 713 (2004)

6. B.M. Jenkins, R.R. Bakker, J.B. Wei, Biomass and Bioenergy, 10, 177-200 (1996)

7. H. Tan, S.-r. Wang, J. Fuel. Chem. Technol, 37, 668-672 (2009)

8. Z.A. Mayer, A. Apfelbacher, A. Hornung, J. Anal. Appl. Pyrol., 94, 170-176 (2012)

9. P. Harmsen, W. Huijgen, L. Bermudez, R. Bakker, Literature Review of Physical and Chemical Pretreatment Processes for Lignocellulosic Biomass, Wageningen UR, Food \& Biobased Research, 2010.

10. D. Park, Y.-S. Yun, J.M. Park, Chemosphere, 60, 1356-1364 (2005)

11. K.O. Davidsson, J.G. Korsgren, J.B.C. Pettersson, U. Jäglid, Fuel, 81, 137-142 (2002)

12. L. Luque, S. Oudenhoven, R. Westerhof, G. V. Rossum, F. Berruti, S. Kersten and L. Rehmann, Biotechnol Biofuels, 9, 242 (2016)

13. D. Vamvuka, S. Troulinos, E. Kastanaki, Fuel, 85, 1763-1771 (2006)

14. T. Sonobe and N. Worasuwannarak, Fuel, 87, 414-421 (2008)

15. S. Zhang, Q. Dong, L. Zhang, Y. Xiong, Bioresource Technol., 199, 352-361(2016)

16. A. Marcilla and M. Beltrain, Polym. Degrad. Stab., 48, 219 (1995)

17. X. S. Wang, Xin-Gui Li and D. Yan, Polym. Degrad. Stab., 69, 361 (2000)

18. J. H. Chena, K. S. Chen and L. Y. Tong, J. Hazard, Mater., 84, 43 (2001)

19. B. J. Holland and J. N. Hay, Thermochim, Acta, 388, 253 (2002)

20. R. A. Ruseckaite and A. Jimenez, Polym. Degrad. Stab., 81, 353 (2003)

21. N. S. Vrandecic, I. Klaric and T. Kovacic, Polym. Degrad. Stab., 84, 31 (2004)

22. P. Budrugeac, E. Segalb, L. A. Perez-Maquedac and J. M. Criado, Polym. Degrad. Stab., 84, 311 (2004)

23. K. Pielichowski and K. Flejtuch, J. Anal. Appl. Pyrol., 73, 131 (2005)

24. A. Saddawi, J.M. Jones, A. Williams, M.A. Wojtowicz, Energy Fuel, 24, 1274-1282 (2010)

25. K. Raveendran, A. Ganesh, K. C. Khilar, Fuel, 74,.1812-1822 (1995)

26. S.D. Stefanidis, E. Heracleous, D. Th. Patiaka, K. G. Kalogiannis, C. M. Michailof and A. A. Lappas, Biomass and Bioenergy, 83, 105-115 (2015)

27. M. T. Reza, R. Emerson, M. H. Uddin, G. Gresham and C. J. Coronella, Biomass Conv. Bioref., 5, 21-31 (2015) 